\title{
Intraperitoneal laparoscopic Mitrofanoff procedure: Ureterocutaneostomy concomitant nephrectomy in a child with kidney transplantation: First case report
}

Pierre Jean Aurelus ${ }^{* 1}$, Hermilo De La Cruz Yáñez ${ }^{1}$, Alfonso Yamamoto Nagano ${ }^{1}$, Amílcar Almonte Pineda ${ }^{1}$, Guillermo Godoy Rabago ${ }^{1}$, and Juan Carlos Martínez Silva ${ }^{1}$

${ }^{1}$ Centro Médico Nacional Siglo XXI “Hospital de Pediatría Dr. Silvestre Frenk Freud” Department of Gastro-transplantation /Instituto Mexicano del Seguro Social (IMSS), México

\begin{abstract}
Introduction: Congenital alteration in the urinary tract represents 20 to $30 \%$ of pediatric patients with end-stage renal disease that required kidney transplantation. Poor bladder emptying and the pooling of mucus may result in an increased incidence of bladder stone formation and infectious that may produce reject and graft loosing. In neuropathic bladder, various tubular structures have been proposed as alternative to drainage the urine. The mean important in this case is to report the outcome in the first intraperitoneal laparoscopic Mitrofanoff procedure using ureter concomitant a native nephrectomy in a child with kidney transplant in our center (Centro Médico Nacional Siglo XXI “Hospital de Pediatría Dr. Silvestre Frenk Freund” IMSS*.
\end{abstract}

Case Report: An 11- year- old female child of $16 \mathrm{~kg}$ of weight and $1.3 \mathrm{~m}$ of size with kidney transplantation had 4 months' history of recurrence urinary track infectious due to a neuropathic bladder and left native kidney hydronephrotic. Intraperitoneal laparoscopic: ureterocutaneostomy concomitant left native nephrectomy was performed, like continence derivation in this child, to drainage the urine and prevented deterioration of graft function.

Conclusion: Laparoscopically, the ureter was used to create a continent conduit between bladder and skin without closing the bladder neck. The patient had a good outcome and we recommended a meticulous dissecting to the ureter-bladder union that should be used like a continence valve; at the same time, it is better placing a drainage for 1-2 days by an historical hydronephrotic with kidney infectious.

Abbreviations: $\mathrm{CIC}^{*}$ : Clean Intermittent Catheterization, IMSS* Instituto Mexicano del Seguro Social

\section{Introduction}

Congenital alteration in the urinary tract represents 20 to $30 \%$ of pediatric patients with end-stage renal disease that required kidney transplantation $[1,2]$. Many patients in this group have neuropathic bladder or incontinent bladder, usually as consequence of spinal dysraphism. Poor bladder emptying and the pooling of mucus may result in an increased incidence of bladder stone formation and infectious that may produce reject and graft loosing $[1,3]$. In neuropathic bladder, various tubular structures have been proposed as alternative to drainage the urine [4]. The Mitrofanoff principle has had a profound effect on incontinence surgery in children, his development of alternative continent bladder access through a continent stoma [1,4]. Others options to urinary continence through the bladder include the ureter, that has been used as an effective channel for catheterization by its mobility, however, it is certainly a more limited resource than small bowel, fallopian tube, bladder tubes and tabularized bowel $[4,5]$.

The mean important in this case is to report the outcome in the first intraperitoneal laparoscopic Mitrofanoff procedure using ureter concomitant a native nephrectomy in a child with kidney transplant in our center (Centro Médico Nacional Siglo XXI "Hospital de Pediatría Dr. Silvestre Frenk Freund" IMSS*.

\section{Case report}

An 11- year- old female child of $16 \mathrm{~kg}$ of weight and $1.3 \mathrm{~m}$ of size with kidney transplantation had 4 months' history of recurrence urinary track infectious due to a neuropathic bladder and left native kidney hydronephrotic. Intraperitoneal ureterocutaneostomy concomitant left native nephrectomy laparoscopic was performed, like continence derivation in this child, to drainage the urine and prevented deterioration of graft function (Figure 1 and Figure 2).

\section{Surgical technique}

Patient receive balanced general anesthesia and placed in a lateral decubitus position and the operating table slightly titled to the reverse Trendelenburg position. By laparoscopic procedure with 4-trocar transperitoneal approach (Figure 3), a 10-mm laparoscopic optic trocar was placed below the umbilicus, two trocars of $5 \mathrm{~mm}$ were placed in the left abdominal side at the middle clavicular line upper and lower the level of the umbilicus, a fourth trocar was placed in the left midaxillary line upper the level of the umbilicus.

We began with a meticulous dissection by mobilizing the left colon up to the spleen flexure, the kidney was identified and by ultrasound dissector (harmonic), we dissected the ureter follow the bladder-ureter union and we perfected the nephrectomy by clipping kidney artery and

Correspondence to: Pierre Jean Aurelus, Hospital de Pediatría Centro Médico Nacional Siglo XXI (Instituto Mexicano Del Seguro Social “IMSS”), México, Tel: +525556276900; E-mail: aurelusjean@yahoo.com.mx

Key words: Intraperitoneal laparoscopic, Ureterocutaneostomy, Mitrofanoff procedure, kidney transplantation

Received: January 20, 2017; Accepted: February 17, 2017; Published: February 21,2017 


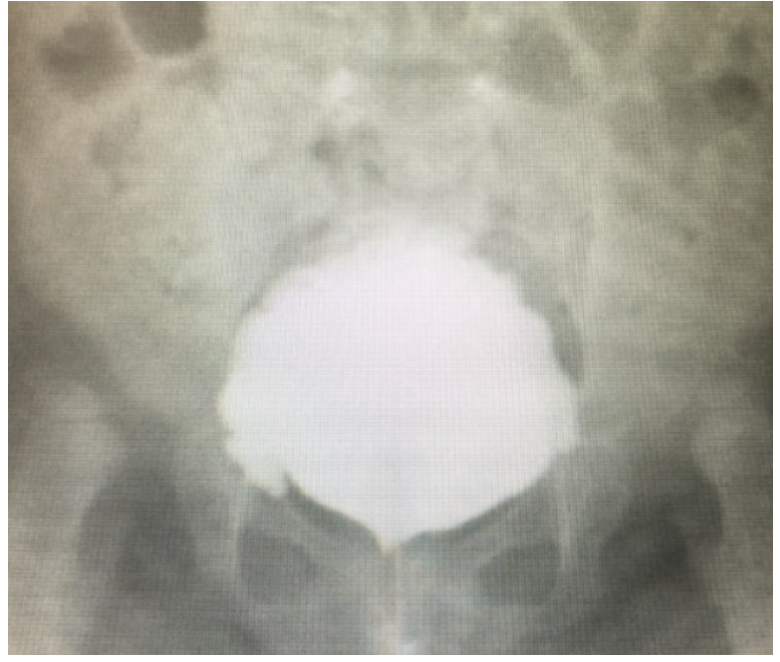

Figure 1. Neuropathic bladder.

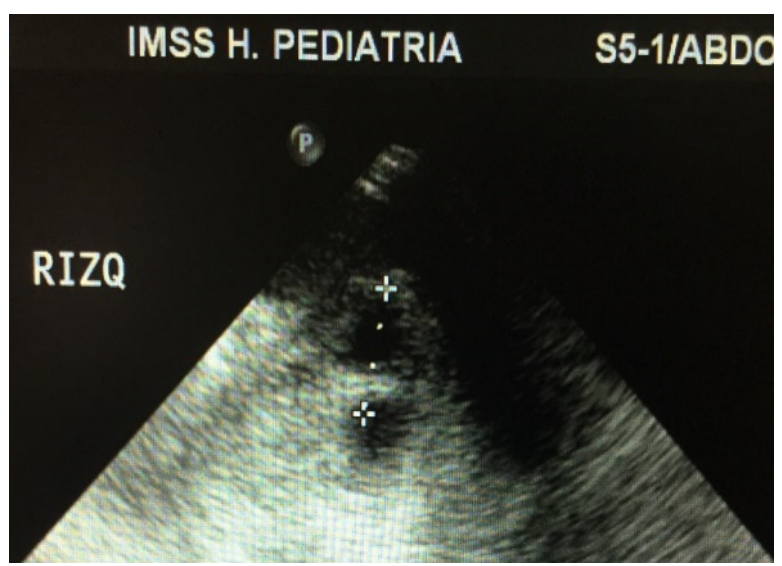

Figure 2. Hydronephrotic left kidney.

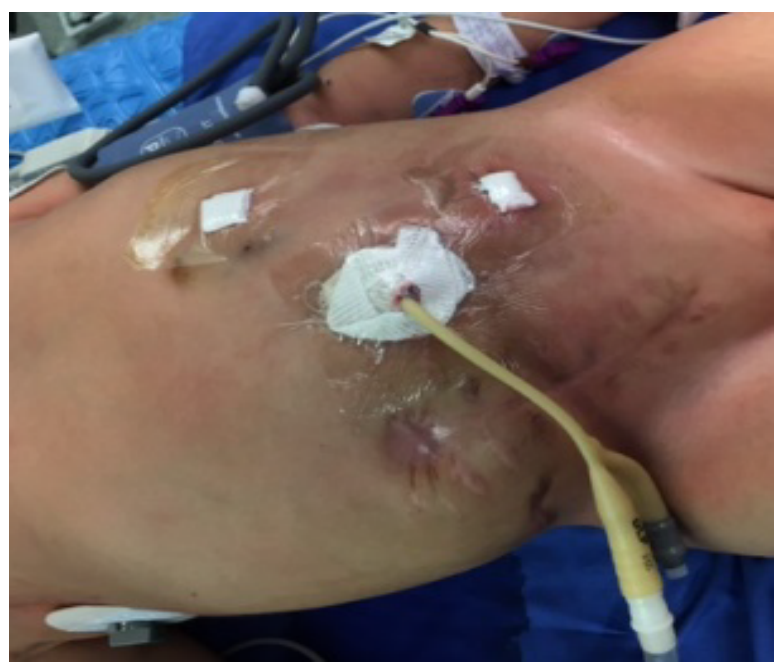

Figure 3. Positioning Trocar

venous. After we used a five-mm optic to remove the kidney at the site of the 10-mm optic without sectioning the ureter at the bladder-ureter union and we had sectioned the native kidney at the pelvis level and we fixed the ureter (kidney pelvis) with Vicryl fourth zero at the optic site (Figure 4)
A $12 \mathrm{Fr}$ umbilicus catheter was inserted by the ureter into the bladder like urinary drainage and ferulization for three weeks (Figure 4). The child was started on oral liquid feeds within 4 hours that had been suspended for an abdominal distended. The catheter was removed after ensuring that the patient and family could catheterize every 3 hours without difficulty previous a control cistograma (Figure 5 and Figure 6).

\section{Discussion}

The type of urinary diversion should be considered carefully, according to the condition of each individual $[1,2,6,7]$. Infectious disorder is an important risk factor that can result in failure of urinary diversion and kidney transplantation or reject $[2,6,8,9]$. Many authors mentioned, when transplant is performed, reconstruction renal function is optimized before undergoing the major procedure and its associated morbidity, the conduit for urinary tract reconstruction and /or augmentation before transplant may be unnecessary $[2,3,8,10]$. Underwent these observations, we performed the derivation after the transplantation in this patient and the aim of this case was to report on the indication, feasibility of intraperitoneal laparoscopic nephrectomy concomitant ureterocutaneostomy derivation and the satisfactory outcome.

Urological complication rates following renal transplantation can be as high as $20 \%$ to $45 \%$ in patient with a history of urinary tract infections; Bladder dysfunction in particular has been associated with higher rate of complications and renal graft failure $[2,10,11]$. The ureter of transplanted kidney needs to be anastomosed to a urine reservoir, with adequate compliance, capacity and efficient voluntary emptying [2,9]. In this child, we had observed a storage of urine bladder that manifested by recurrence infection of the urinary tract due to a High compliance bladder and a raised intravesical pressure that were considered the indications to create a continent conduit between bladder and skin $[6,8,9,11]$. The duration of operation was 146 minutes compared others studies that mentioned 111 minutes (range 85 to 175) for laparoscopic ureterocutaneostomy [5,12]. Small atrophic kidneys can be quickly removed with unilateral or bilateral lumbotomies, which are generally well tolerated. Laparoscopic and retroperitoneoscopic approaches to native nephrectomy have become relatively commonplace $[11,13]$. In our patient, we removed the native kidney by an intraperitoneal laparoscopic nephrectomy.

Kaeffer and Retik reported an initial continence rate of $82 \%$ and ultimately $96 \%$ : Suze et al reported a $98 \%$ continence rate, our patient had continence after the procedure by the meticulous dissecting to

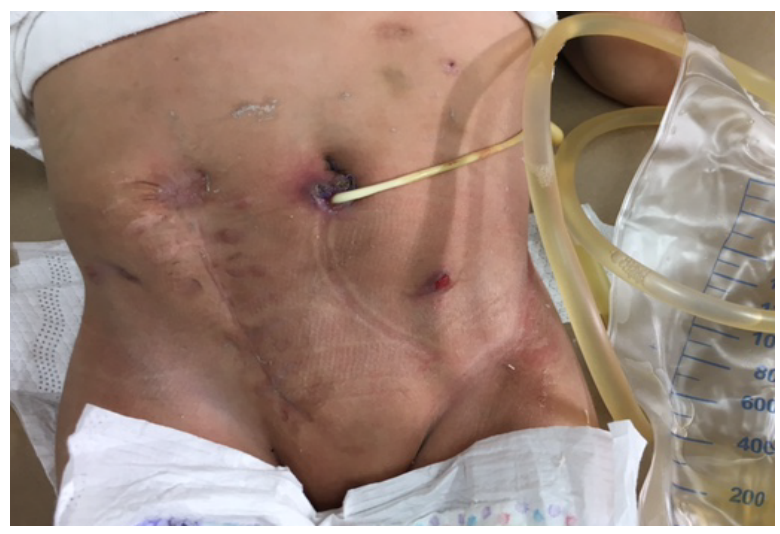

Figure 4. Ten days postoperatively. 


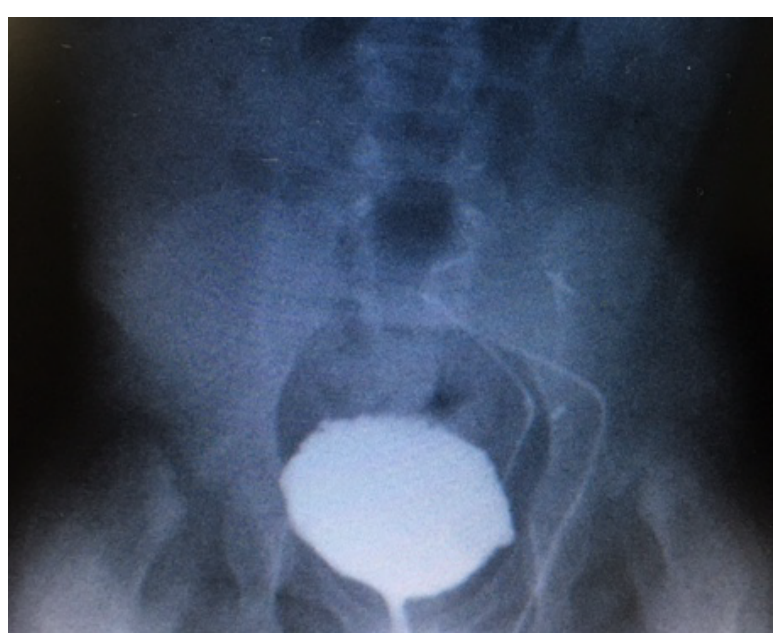

Figure 5. Control cistograma

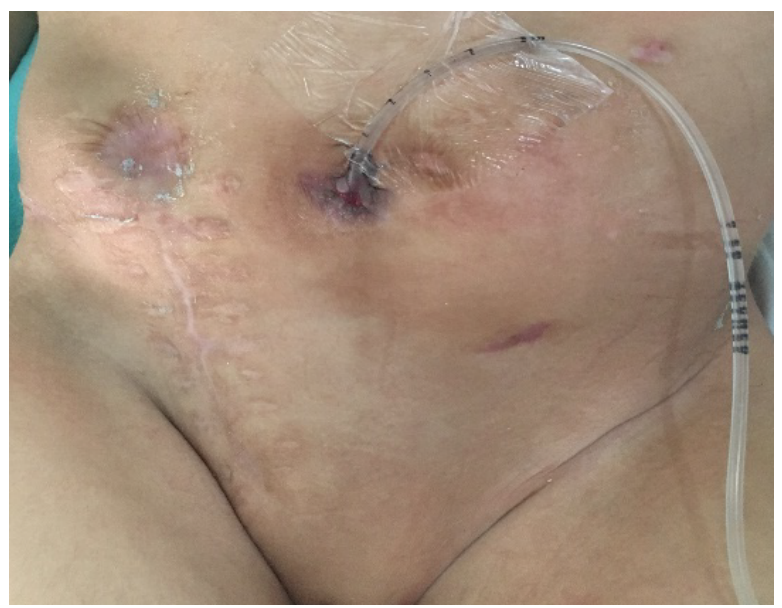

Figure 6. Cosmetic aspect and CIC

the ureter-bladder union without disinserted the ureter and preserved some part of this union, like a valve to control urine continence and the patient was dry [14]. In this case like mentioned the literature, continence was defined as being dry day and night with a minimum of a 3-hour voiding (voiding o clean intermittent catheterization "CIC") interval [15]. Catheterization problems started at a mean of 4.8 weeks and pouch formation was noted at a mean of 6.2 months after surgery, fortunately our patient had 12 weeks with a functional conduit [11]. Lapides and colleagues published a follow up study of 255 children on CIC and noted that although $56 \%$ of patients showed bacteriuria, only $11 \%$ actually developed a symptomatic urinary tract infection $[9,16]$.

Infections and stomal-related complications are common in continent urinary diversion about 36\% [7,9,14]. A randomized, controlled trial has shown that it is also not necessary for children on CIC to be on prophylactic antibiotics, however, in patient with kidney transplant we recommended the prophylactic because immunosuppressive medication may influence in the outcome $[6,7,9,17]$. The incidence of stomal stenosis with appendix was $24 \%$, there were more complications in umbilical stomal, but the reason is unclear $[1,2,4,18]$. These complications contribute significantly to morbidity and mortality rates $[2,7,15]$. Intraperitoneal Laparoscopic derivation of ureter concomitant nephrectomy due severe hydronephrotic kidney was feasible and without important complications in our patient. She had a good outcome without stomal leakage, necrosis or fibrosis of the conduit and perforation like mentioned the literature $[11,18]$. On the other hand, there is no similarly intraperitoneal laparoscopic report in the literature after kidney transplant. In this case, we had anastomosed the ureter nearly the umbilicus to avoid stenosis and catheterization problems. In addition, the stoma should be as cosmetically pleasing as possible. Traditionally, the umbilicus and the lower abdomen have been the commonest sites [11] (Figure 6).

In children approaching adolescent and adulthood, the perceive benefits of a minimally invasive approach such as lower-analgesic requirements improved recovery time and improved cosmesis might be more apparent than in younger children and the median length of stay was 7 days. In our patient, the blood loss was $50 \mathrm{cc}$ versus 46 $\mathrm{cc}$ that mentioned the literature without nephrectomy, we had liquid diet in day two because he had abdominal distended due to peritoneal secretion, for that, we had placed a drainage in the site of the lower trocar for 3 days and we had a satisfactory outcome with a length stay of 6 days $[5,12]$. Concerning the time to performed the procedure many studies concluded that graft survival is not adversely affected compared to historical controls when a kidney transplantation is drained into a urinary conduit or augmented bladder $[2,8,10]$. Other study mentioned that kidney transplant recipients with prior bladder surgery have an increased risk of graft failure and an increased risk of infectious urinary complications. These risks should be considered in recipient selection and post-transplant management like we performed in our patient [7].

\section{Conclusion}

In this case, the technique had offered a tube of adequate lumen size and length, with easy catheterization a reliable blood supply and the versatility to be combined with a simultaneous, intraperitoneal native laparoscopic nephrectomy. The ureter was used to create a continent conduit between bladder and skin without closing the bladder neck. The patient had a good outcome and we recommended a meticulous dissecting to the ureter-bladder union that should be used like a continence valve; at the same time, it is better placing a drainage for 1-2 days by an historical hydronephrotic with kidney infectious.

\section{Acknowledgements}

To IMSS, Saint Justin Jean, Charlotte Jean Ortega, Pierre Jean Cano, Maria Del Carmen Ortega Rodríguez, André Jean, Franck Jean, Imene Jean, Lucrece Jean, Flores Jean, Luisa Yesenia Navarro Sánchez, Yma Alusma, and Jean Family.

\section{Conflicts of interest}

There are no conflicts of interest to disclose.

\section{References}

1. Leslie Jeffrey A, DussingerAndew M, Meldrum Kirstan K (2007) Creation of continence mechanisms (Mitrofanoff) without appendix: The Monti and spiral Monti procedures. UrolOncol 25: 148-153. [Crossref]

2. Slagt Inez KB, IJzermans Jan NM, Alamyar Mustafa, et al. (2013) Long-term outcome of kidney transplantation in patients with a urinary conduit: a case -control study. IntUrolNephrol 45: 405-411.

3. Antonio C, MeraneyAM, Abarzua-Cabezas F,Lally A, Brown M, et al. (2014)Singlestage Renal Transplantation-urinary Diversion: A Novel Surgical Approach. Urology 84: 232-236. [Crossref]

4. Castellan MA, Gosalbez Rafael Jr, LabbieA (1999) Clinical applications of the Mont procedure as a continent catheterizable stoma. Urology 54(1):152-156. [Crossref]

5. Rajendra BN, Mallikarjun R, Shishir D, Vikram P,HiremathMB, et al. (2012) Laparoscopic Mitrofanoffappendicovesicostomy: Our experience in children, Indian J Urol 28:28-31. 

case report

6. Teng L, Wang C, Li J (2013) Long-term out come of simultaneous or stage durinary diversion and kidney transplantation. Urol Int 91: 310-314. [Crossref]

7. Srinivasan D, Stoffel JT, Mathur AK, Kapeles S, Bradley K, et al. (2016) LongTermOutcomes of Kidney Transplant Recipients with Bladder Dysfunction: A SingleCenter Study. Ann Transplant 21: 222-234. [Crossref]

8. Al-Khudairi N, Paul R, Divyesh YD, Christopher R, et al. (2013) Interventions for impaired bladders in paediatric renal transplant recipients with lower urinary tract dysfunction. Transplant International; 26:428-434. [Crossref]

9. Choi YS, Kim KS, Choi SW, Bae WJ, Hong SH, et al. (2016)Ureteral Complication in Kidney Transplantation: Analysis and Management of 853 Consecutive Laparoscopic Living-Donor Nephrectomies in a Single Center. Transplant Proc 48: 2684-2688. [Crossref]

10. Christman Matthew S, Canning Douglas A, Schast Aileen P, et al. (2013)Renal Transplantation into a Diverted Urinary System-Is It Safe in Children? J Urol190: 678682. [Crossref]

11. Marie-Klaire F, Padraig SM (2010)Educational article: The Mitrofanoff procedure Journal of PediatricUrology 6:330-337.
12. Metzelder M, Petersen C, Ure B (2008) Laparoscopic ureterocutaneostomy for urinary diversion in selected infants. Eur J PediatrSurg 18: 86-88. [Crossref]

13. Sackett Daniel D, Singh Pooja, Lallas Costas D (2011) Urological involvement in renal transplantation. Int J Urol 18: 185-193. [Crossref]

14. De Ganck J, Everaert K, Van Laecke E, Oosterlinck W, Hoebeke P (2002) A high easy-to-treat complication rate is the price for a continent stoma. BJU Int 90: 240-243. [Crossref]

15. Elshal Ahmed M, Abdelhalim Ahmed, Hafez Ashraf T, et al. (2012) Ileal Urinary Reservoir in Pediatric Population: Objective Assessment of Long-termSequelaewith Time-to-eventAnalysis. JUrol 79(5).

16. Kass EJ, Koff SA, Diokno AC, Lapides J (1981) The significance of bacilluria in children on long-term intermittent catheterization. J Urol126: 223-225. [Crossref]

17. Clarke SA, Samuel M, Boddy SA (2005) Are prophylactic antibiotics necessary with clean intermittent catheterization? A randomized controlled trial. J PediatrSurg 40:568-571.

18. Knight RB, Hudak SJ, Morey AF (2013) Strategies for open reconstruction of upper ureteral strictures. Urol Clin North Am 40: 351-361. [Crossref]

Copyright: @2017 Aurelus PJ. This is an open-access article distributed under the terms of the Creative Commons Attribution License, which permits unrestricted use, distribution, and reproduction in any medium, provided the original author and source are credited. 